\title{
Erratum to: Time intervals from aneurysmal subarachnoid hemorrhage to treatment and factors contributing to delay
}

\author{
Menno Robbert Germans • Jantien Hoogmoed • \\ H. A. Stéphanie van Straaten - Bert A. Coert • \\ W. Peter Vandertop - Dagmar Verbaan
}

Published online: 7 August 2014

(C) Springer-Verlag Berlin Heidelberg 2014

Erratum to: J Neurol (2014) 261:473-479

DOI 10.1007/s00415-013-7218-2

In the original article, corresponding author's (Menno Robbert Germans) given name has been published incorrectly. The correct Given name should be Menno Robbert.

The online version of the original article can be found under doi:10.1007/s00415-013-7218-2.

M. R. Germans $(\bowtie) \cdot$ J. Hoogmoed · H. A. S. van Straaten ·

B. A. Coert - W. Peter Vandertop - D. Verbaan

Academic Medical Center, Amsterdam, The Netherlands

e-mail: mrgermans@hotmail.com 